IZA DP No. 6273

\title{
The Indian Ultrasound Paradox
}

Mevlude Akbulut-Yuksel

Daniel Rosenblum

January 2012 


\title{
The Indian Ultrasound Paradox
}

\author{
Mevlude Akbulut-Yuksel \\ Dalhousie University, \\ HICN and IZA \\ Daniel Rosenblum \\ Dalhousie University \\ and CGHR \\ Discussion Paper No. 6273 \\ January 2012 \\ IZA \\ P.O. Box 7240 \\ 53072 Bonn \\ Germany \\ Phone: +49-228-3894-0 \\ Fax: +49-228-3894-180 \\ E-mail: iza@iza.org
}

Any opinions expressed here are those of the author(s) and not those of IZA. Research published in this series may include views on policy, but the institute itself takes no institutional policy positions.

The Institute for the Study of Labor (IZA) in Bonn is a local and virtual international research center and a place of communication between science, politics and business. IZA is an independent nonprofit organization supported by Deutsche Post Foundation. The center is associated with the University of Bonn and offers a stimulating research environment through its international network, workshops and conferences, data service, project support, research visits and doctoral program. IZA engages in (i) original and internationally competitive research in all fields of labor economics, (ii) development of policy concepts, and (iii) dissemination of research results and concepts to the interested public.

IZA Discussion Papers often represent preliminary work and are circulated to encourage discussion. Citation of such a paper should account for its provisional character. A revised version may be available directly from the author. 


\section{ABSTRACT}

\section{The Indian Ultrasound Paradox}

The liberalization of the Indian economy in the 1990s made prenatal ultrasound technology affordable and available to a large fraction of the population. As a result, ultrasound use amongst pregnant women rose dramatically in many parts of India. This paper provides evidence on the consequences of the expansion of prenatal ultrasound use on sex-selection. We exploit state-by-cohort variation in ultrasound use in India as a unique quasi-experiment. We find that sex-selective abortion of female fetuses is rising in states with a slow expansion of ultrasound relative to those states with a rapid expansion of ultrasound. Thus, our findings suggest that the recent rapid spread of ultrasound is not causing higher rates of sex-selection in India.

JEL Classification: J13, J16, O1

Keywords: $\quad$ ultrasound, sex-selective abortion, India

Corresponding author:

Mevlude Akbulut-Yuksel

Department of Economics

Dalhousie University

6214 University Avenue

Halifax, NS, B3H $3 J 5$

Canada

E-mail:mevlude@dal.ca

\footnotetext{
* We thank Prashant Bharadwaj, Gustavo Bobonis, Aruna Dhara, Lars Osberg, Shelley Phipps, Gerard van den Berg, Courtney Ward and Mutlu Yuksel as well as seminar participants at Mount Allison University and Dalhousie University for useful comments and discussions. The authors bear the sole responsibility for any errors that remain.
} 


\section{Introduction}

The liberalization of the Indian economy starting in the 1990s sparked an increase in ultrasound availability. Indian government data shows that the number of ultrasound machines manufactured in India increased rapidly between 1988 and 2003 with an especially marked increase after 1994 (George, 2006). In 1994, companies such as GE began partnering with local companies and producing ultrasound machines. In 2006, annual sales rose to $\$ 77$ million (Wonacott, 2007). The cost of an ultrasound test is in the range of $\$ 10$ to $\$ 20$ (Ganatra and Hirve, 2002), and ultrasound has become easy to access even in many rural areas. Recent research attributes the rise in sex-selection in India to the introduction of ultrasound as a relatively cheap and safe way to determine the sex of a fetus (Arnold et al., 2002; Bhalotra and Cochrane, 2010). Research has also confirmed high levels of sex-selective abortions in India, causing an estimated half a million missing women in India per year (Jha et al., 2006, 2011; Bhalotra and Cochrane, 2010).

To date there is limited formal evidence on the effects of the continued spread of ultrasound technology on missing women in India. On the one hand, ultrasound can be misused for sex-selective abortion, exacerbating the already skewed sex-ratio in India. On the other hand, ultrasound technology has legitimate medical benefits that may lead to general improvements in child and maternal health. Thus, it is relevant to public health policy to identify whether

there is a significant negative consequence of the increasing availability of ultrasound and to quantify such an effect if it exists.

We contribute to the existing research by showing, contrary to common belief, that the recent rapid spread of ultrasound in India did not cause a concomitant rise in sex-selection. To clarify, throughout our paper we define sex-selection as the abortion of female fetuses until a male child is born as opposed to infanticide or excess female mortality. This paper provides a novel examination of the consequences of prenatal ultrasound use on the sex outcomes of children at birth. This is the first paper to use the large District Level Health Surveys (DLHS) to examine the spread of ultrasound in India, giving us a sample of close to half a million 
births. Specifically, we use state-by-cohort variation in ultrasound use in India arising from the large-scale increase in ultrasound availability in the 1990s as a unique quasi-experiment. We rigorously quantify the consequences of the increase in the use of ultrasound on sex-selection in two ways. First, we examine the association over time between a mother's individual ultrasound use during pregnancy and the sex of her child. Second, we use state-year level ultrasound use in India to control for individual reporting bias in addition to estimating the effects of state-level trends in ultrasound use on sex-selection.

This is the first paper to use state-level ultrasound exposure to find that the rapid rise of ultrasound in the 2000s in India did not cause an increase in sex-selective abortion. Our results show that the more rapid the expansion of ultrasound, the fewer the sex-selective abortions of female fetuses. These results are robust to using alternative samples and specifications, including controlling for state-year level GDP per capita.

In order to interpret our findings and check the reliability of our data, we estimate whether pre-trends in sex-selection are correlated with the rise in ultrasound use in the 2000s. We find no statistically significant relationship between the sex at birth of children born in the 1980s, before the large-scale introduction of ultrasound in India and when sex-selective abortion was rare, and the spread of ultrasound in the 2000s. This finding helps to confirm that our main estimates are not an artifact of our data. However, we find that states with a rapid rise in ultrasound use in the 2000s are the states where parents were more likely to give birth to a son in the 1990s. Thus, states which had an initial increase in sex-selection in the 1990s, reversed their trend relative to the rest of India in the 2000s, despite the fact that ultrasound use grew much more quickly in these states. We conclude that the recent rapid increase in ultrasound use in several states of India is not causing a rapid rise in sex-selection in those states.

The remainder of the paper is organized as follows. Section 2 provides a brief background on missing women and the spread of ultrasound technology in India. Section 3 describes the data used in the analysis. Section 4 provides a broad overview of trends in ultrasound use and sex-selection. Section 5 discusses the estimation strategy to test the relationship between ultrasound use and sex-selection. Section 6 presents the main results, extensions, and robustness 
checks. Section 7 concludes.

\section{Background}

The missing women problem, as elucidated by Sen (1990), posits that if females received the same care and resources as males, there would be many more females alive today than there actually are. Several studies estimate the magnitude of the missing women problem (Coale (1991), Klasen (1994), Anderson and Ray (2008)). The higher than normal male-female sex ratio before the 1980s is mostly attributed to higher female mortality. However, once the technology for sex-selective abortion became widely available in the 1980s and the 1990s (in China and India respectively), the sex ratio increased at a faster rate. ${ }^{1}$ Populations using sex-selective abortion may be doing so for strong economic reasons (Rosenblum, 2011). However, there has been little previous research on whether wide-scale ultrasound availability is to blame for the rise in sex-selection.

Bhalotra and Cochrane (2010) show that the sharp increase in the Indian male-female sex ratio at birth coincides with the increased prevalence of ultrasound in the 1990s. A key difference between Bhalotra and Cochrane (2010) and our paper is that rather than looking at differences in the timing of the initial availability of sex-selection, we look at differences in trends in actual ultrasound use over time. In other words, our paper focuses on the effects of the spread of ultrasound use after the introduction of ultrasound, rather than the effects of the introduction of ultrasound itself.

Arnold and Parasuraman (2009) examine the relationship between reported ultrasound use and pregnancy outcomes in the 2005-06 Indian National Family Health Survey. They show that there is a positive correlation between a mother's individual ultrasound use and the probability a child is born male. If we ignore time trends, we find the same positive correlation between ultrasound use and sex-selection. Our paper differs in that we investigate whether changes in state-level ultrasound use over time are associated with changes in sex-selection. Our novel

\footnotetext{
${ }^{1}$ Hvistendahl (2011) provides an excellent overview of the technological and political history of sex-detection and its consequences.
} 
approach shows that, although the initial introduction of ultrasound led to sex-selection, the rapid rise in ultrasound afterwards did not cause more sex-selection. Our paper complements Chen et al. (2011) who investigate the effect of the spread of ultrasound availability on sexselection in China. We do not find, as does Chen et al. (2011), that greater availability causes more sex-selective abortions.

\section{Data and Descriptive Statistics}

We combine the 2002-2004 District Level Household Survey (DLHS II) and the 2007-2008 District Level Household Survey (DLHS III) to analyze the impact of the spread of ultrasound over time in India. The DLHS I data set is not used in the analysis because it reports no information on ultrasound use. These surveys were conducted by the Government of India through the International Institute for Population Sciences (IIPS). Both surveys are nationally representative at the district level and cover all of the approximately 600 districts in India. The DLHS II surveyed 507,571 ever-married women aged 15-44. The DLHS III surveyed 643,944 ever-married women aged 15-49.

Essential to the purpose of this paper, the DLHS II and DLHS III provide information on mothers' ultrasound use during their most recent pregnancy, which covers the years 1999 to 2008. Using this information, we create a measure of the availability of ultrasound for pregnant women at the state-year level. To simplify our analysis, we restrict the sample to children of birth order four or less. ${ }^{2}$ Furthermore, since twins represent a different effect on the household compared to a singleton, we drop households with twins from the analysis. The resulting sample for the main analysis consists of 498,865 children born between 1999 and 2008 .

The DLHS II and III ask demographic questions as well as detailed questions about fertility and child care. The DLHS II includes full birth histories of mothers, while the DLHS III only includes details on children born since January, 2004. For our main estimates we only use information about births between 1999 and 2008, effectively reducing the DLHS II full birth

\footnotetext{
${ }^{2}$ All of our main estimates are robust to including all children.
} 
histories into birth histories similar to those reported in the DLHS III. Both surveys ask detailed questions about the most recently born child. In particular they report whether an ultrasound test was used during the last pregnancy. Reporting rates for this question are close to 100 percent. The DLHS II reports ultrasound use regardless of the outcome of the pregnancy (live birth, abortion, still birth, or miscarriage), while the DLHS III reports ultrasound use except if the pregnancy ended in a miscarriage. To minimize reporting bias and to provide consistency between surveys, we only use ultrasound information if that pregnancy resulted in a live birth. ${ }^{3}$

We use reported ultrasound use of the most recent pregnancy in two ways. First, we directly estimate whether a mother's ultrasound use during pregnancy is correlated with the sex of her most recent child at birth. This approach is problematic because there may be underreporting of ultrasound use for parents who use ultrasound for sex-selective abortion. Furthermore, it only allows us to investigate the effects of ultrasound use on the subset of most recently born children. In order to resolve these issues, we use reported ultrasound use to calculate the average ultrasound use in a given year and state. We call this average state-year level of ultrasound use "ultrasound exposure" because it indicates the likelihood that ultrasound was used for a child born in that year and state even if we do not directly know whether ultrasound was used during that child's pregnancy. This second approach also allows us to determine whether state-level trends in ultrasound use are associated with state-level trends in the sex-ratio at birth.

In addition, the full birth histories of the DLHS II allow us to explore the relationship between sex-selective abortion in Indian states before 1999 and the later diffusion of sex determination technologies in the 2000s. That is, this data allows us to perform a falsification test of whether ultrasound use from 1999 to 2008 is correlated with the pre-trends in the sex of children at birth in the 1980s when sex-selective abortion was rare. It also allows us to test whether trends in sex-selective abortion in the 1990s are related to the future expansion of ultrasound use.

Table 1 shows descriptive statistics for the dataset. The mean values are separated by child birth order in columns (1) through (4). As found elsewhere (Bhalotra and Cochrane, 2010;

\footnotetext{
${ }^{3}$ Our estimates are robust to calculating ultrasound exposure using the ultrasound data from the pregnancies that end in a live birth combined with the small fraction of pregnancies that do not end with a live birth.
} 
Ebenstein, 2007; Jha et al., 2011; Portner, 2010; Rosenblum, 2010), the proportion of male children at birth is close to normal for first-borns and then rises for higher parities. Since better-off parents tend to have fewer children, parents' years of schooling are higher on average for lower order births. For the same reason, scheduled caste and scheduled tribe households, as well as rural households, are more likely to represent parents of higher order children. ${ }^{4}$

[Table 1 about here.]

\section{Overview of Ultrasound Use and Sex-Selection}

One may expect that the spread of ultrasound use across India would exacerbate sex-selective abortion. This no doubt happened in the 1990s, as shown by Bhalotra and Cochrane (2010). However, after the initial burst of sex-selective abortion in the 1990s, it is not clear that the increasing availability of ultrasound in Indian states will increase the incidence of sex-selective abortions in states where ultrasound machines are already available. Initial evidence that the spread of ultrasound use may not be causing a rise in sex-selection can be seen from graphs constructed from the DLHS II and III. First, Figure 1 shows the diffusion of ultrasound use by region and year of birth. ${ }^{5}$ Each data point indicates the percent of most recent pregnancies in which ultrasound was used during the pregnancy in a given region-year. Ultrasound use has spread most quickly in the south, north, and west of India. Northern India has the highest male-female sex ratio in India and ultrasound use rose from 14 percent in 1999 to 40 percent in 2008. Western India also has a high male-female sex ratio at birth and ultrasound use increased from 29 percent in 1999 to 48 percent in 2008. However, southern India, which generally has a normal male-female sex ratio, saw the most rapid increase in ultrasound use, growing from 26 percent in 1999 to 77 percent in 2008. The other regions of India saw modest increases in

\footnotetext{
${ }^{4}$ Higher order children may be more likely to live in states with less access to health services, including ultrasound. We control for these possibilities in our estimates by including household demographic characteristics, birth order dummies, and state fixed effects.

${ }^{5}$ North = Delhi, Haryana, Himachal Pradesh, Punjab, Rajasthan, and Uttaranchal/Uttarakhand. Center $=$ Uttar Pradesh and Madhya Pradesh. West $=$ Gujarat and Maharashtra. South $=$ Andhra Pradesh, Karnataka, Kerala, and Tamil Nadu. East $=$ Bihar, Chhatisgarh, Jharkand, Orissa, and West Bengal. Northeast $=$ Arunachal Pradesh, Assam, Manipur, Meghalaya, Mizoram, Sikkim, and Tripura.
} 
ultrasound use, rising from 5-8 percent in 1999 to 10-13 percent in 2008.

[Figure 1 about here.]

For an overview of patterns in sex-selection, we examine the sex-ratio at birth with the sample separated into regions with fast ultrasound expansion (north, west, and south) and slow ultrasound expansion (center, northeast, east). We further restrict the sample to children at a high risk of sex-selection: second-born children who have a first-born sister. ${ }^{6}$ Figure 2 shows the sex-ratio at birth for these children from 1989 to 2008, divided into the fast and slow growing ultrasound parts of India. The data is smoothed over three-year averages. Sex-selection has been rising over time in both regions. The pattern shows a gap between the slow and fast ultrasound growth regions starting in the early 1990s, but that gap begins to close in the 2000s. Sex-selection appears to have leveled off in the fast growth regions, while it is increasing in the slow growth regions. Thus, despite the rapid increase in ultrasound use in the fast growth regions, sex-selection in these regions appears to be falling relative to the slow growth regions. Appendix A shows further evidence of the disconnect between ultrasound use and regional sex-ratios using the 1991, 2001, and 2011 Indian Censuses. $^{7}$

[Figure 2 about here.]

Figure 3 shows a declining gap in the sex-ratio at birth between pregnancies in which a mother indicates ultrasound was used versus mothers who did not use ultrasound. The graph shows the proportion of males born across India of birth order two and higher by birth year. First births are ignored because there is no evidence of sex-selective abortion at the first parity (Jha et al., 2011; Bhalotra and Cochrane, 2010; Portner, 2010; Rosenblum, 2010). See Figure 4 for the proportion of recent male births for first births. There is no average difference in sex outcomes between first pregnancies which used ultrasound and those that did not.

A biologically normal proportion of males to females at birth, which we see in developed countries, is in the 51-52 percent range. Although some Indian states have proportions much

\footnotetext{
${ }^{6}$ There is no difference in the sex-ratio between regions if the first-born child is male.

${ }^{7}$ The census sex ratios reflect both the effects of sex-selection and excess female mortality, and, hence, only show indirect trends in sex-selection over time in India.
} 
higher than this, Figure 3 shows that the recent trend in India is towards a lower proportion of males born at birth order two and higher. The average proportion of males at birth is always higher in the ultrasound use group. Yet, the sex-ratio gap has been closing over time between pregnancies in which ultrasound is used and those where it is not used. There is no statistically significant difference in the proportion of children born male for the ultrasound and non-ultrasound groups in 2007 and 2008. While ultrasound use has been rising, it has become less and less correlated with sex-selection. Therefore, it is unlikely that the increased ultrasound use is driven by an increased demand for sex-selection. This is not to say that ultrasound is not used for sex-selection. It certainly is, and it can explain why sex ratios at birth are still quite skewed towards males in several regions of India. Rather, the increase in ultrasound use does not appear to be causing an increase in sex-selection.

[Figure 3 about here.]

[Figure 4 about here.]

\section{Estimation Strategy}

We conduct our empirical analysis using two methods. First, we estimate the association between ultrasound use and child sex at birth using the actual ultrasound use of the mother for her most recent birth. This method gives an initial indication of the trends in the correlation between ultrasound use and sex-selection. However, this estimation method does not account for the possible systematic underreporting of ultrasound use among mothers who have used it for sex-selection, nor does it allow us to use the large number of births in the data that are not the most recent ones. To resolve these problems, our second estimation method uses average state-year ultrasound use as a proxy for ultrasound availability in a given birth-year. In addition, this second method allows us to analyze state-level trends in ultrasound use. 


\subsection{Mother's Ultrasound Use}

In this section, we present our estimation equation to analyze the association between ultrasound use and the probability of having a male child for most recent births. This equation more formally estimates the relationship found in Figure 3. In particular, we estimate the following linear regression:

$$
Y_{i j t}=\alpha+\beta \text { Ultrasound }_{i j t}+\gamma Y O B_{t}+\psi \text { Ultrasound }_{i j t} * Y O B_{t}+\delta_{j}+\pi^{\prime} \mathbf{X}_{i j t}+\varepsilon_{i j t}
$$

where the outcome, $Y_{i j t}$, is 1 if the most recently born child for mother $i$ in state $j$ and year $t$ is male and 0 if female. Ultrasound ${ }_{i j t}$ is a dummy variable which takes a value of 1 if the mother reported ultrasound was used during her pregnancy. A positive $\beta$ implies that sexselection is more likely to occur among mothers who use ultrasound during their pregnancy. $Y O B_{t}$ is the child's year of birth, treated as a continuous variable and normalized so that 1999 is year 0 and 2008 is year 9. We include an interaction term of ultrasound use and the child's year of birth to assess trends in the correlation between ultrasound and sex-selection over time. A positive coefficient for this interaction term indicates that the likelihood of ultrasound technology being used for sex-selection has been increasing over the last decade, while a negative coefficient indicates the opposite. Outside of the interaction term, $Y O B_{t}$ controls for any linear time trend in the sex-ratio at birth that is common in all of India. $\mathbf{X}_{i j t}$ is a vector of household characteristics including mother's and father's education, mother's age at birth, birth order dummy variables, caste and religion dummies and a rural dummy. $\delta_{j}$ are state-specific fixed effects, controlling for the fact that states may be systematically different from each other. $\varepsilon_{i j t}$ is a random, idiosyncratic error term. In all of our estimates, robust standard errors are clustered by state.

Since sex-detection is illegal in India, ${ }^{8}$ one concern of this approach is that parents who use ultrasound for sex-selective abortion may under-report their ultrasound use. We only use

\footnotetext{
${ }^{8}$ Getting an ultrasound test is not illegal. It is just illegal for the doctor or technician to reveal the sex of a fetus to parents.
} 
responses about ultrasound use if there was a live birth afterwards. Therefore, it is unlikely that the respondents are worried that the surveyor will think they used ultrasound for sex-selection. However, it still may be the case that parents are less likely to report ultrasound use if they had used it for sex-selection in the past. Moreover, Equation (1) assumes that controlling for observables, the error term $\varepsilon_{i j t}$ is uncorrelated with mother's ultrasound use. However, if mothers that use ultrasound technology for sex-selection are systematically different from the rest of the population in observable and unobservable ways, OLS estimations would be biased. These concerns will be partly addressed in the next section when state-year level ultrasound exposure, as opposed to mother's individual ultrasound use, provides a measure of the availability of ultrasound.

\subsection{State-Year Level Ultrasound Exposure}

In this section, we describe our strategy for estimating the effect of the spread of ultrasound over time on sex-selection. This strategy exploits the plausibly exogenous state-by-cohort variation in average ultrasound use. We refer to the state-year mean ultrasound use as "ultrasound exposure". The proposed estimate of the average treatment effect of ultrasound exposure on the probability that a child is born male is given by $\beta$ in the following baseline state and child's year of birth fixed effects equation:

$$
Y_{i j t}=\alpha+\beta \text { ltrasound }_{j t}+\delta_{j}+\gamma_{t}+\pi^{\prime} \mathbf{X}_{i j t}+\varepsilon_{i j t}
$$

where $Y_{i j t}$ is the sex of child $i$ born in state $j$ in year $t$, and now includes all children in the data born between 1999 and 2008 (which we will refer to as the "2000s"). Ultrasound is the measure of ultrasound exposure in state $j$ in year $t . \gamma_{t}$ are child year of birth fixed effects, controlling for the likely secular changes across birth cohorts. The other variables are the same as in Equation (1).

As in the previous section, we only use average ultrasound use for most recent pregnancies 
where there was a live birth afterward. If women are less likely to report ultrasound use if they have ever used it for sex-selection, it is possible that we are underestimating ultrasound use in states where sex-selection is more common. Since we include state fixed effects in our analysis, if underreporting rates are similar over time in the same state, this underreporting will not affect our estimates. However, our results will be confounded if state-level trends in sex-selection are correlated with state-level trends in reporting of ultrasound use. This problem should be mitigated by the fact that the proportion of pregnancies that end in sex-selection represent a small number of total pregnancies an, in addition, the large variation in average reported ultrasound use across Indian states. Therefore, we believe that state-year level ultrasound exposure captures the availability of ultrasound in each Indian state in the given year rather than systematic reporting bias. ${ }^{9}$

In order to interpret $\beta$ as the causal effect of ultrasound exposure on the child sex ratio, we must assume that had ultrasound not become available in India, the difference in the sex-ratio at birth would have been the same across states with varying intensity of ultrasound availability. We assess the plausibility of this assumption by performing a falsification test/control experiment where we repeat the analysis using only cohorts who were born in the 1979-1988 time period (which we will refer to as the "1980s"), before the wide-scale introduction of ultrasound in India. We also test for differential state trends in the probability of being born male for the 1989-1998 time period (which we will refer to as the "1990s") when ultrasound started to become widely available. We estimate Equation (2) using 10 and 20 year birth lags. That is, we assign the actual ultrasound exposure of year $1999+\mathrm{N}$ to children who were born in $1979+\mathrm{N}$ (20 year lag) or 1989+N (10 year lag). In particular, we estimate the following equation separately for cohorts born in the 1980s and the 1990s, respectively:

$$
Y_{i j t-n}=\alpha+\beta \text { ltrasound }_{j t}+\delta_{j}+\gamma_{t-n}+\pi^{\prime} \mathbf{X}_{i j t-n}+\varepsilon_{i j t-n}
$$

\footnotetext{
${ }^{9}$ Our estimates are robust to different specifications of ultrasound exposure. For example, the estimation results are qualitatively similar if we use state-year-urban and state-year-rural ultrasound exposure measures.
} 
where $n$ takes the value of 20 for cohorts born between 1979 and 1988 and the value of 10 for cohorts born between 1989 and 1998. $Y_{i j t-n}$ is the sex of a child $i$ born in state $j$ in year $t-n$. Ultrasound $_{j t}$ is the measure of ultrasound exposure in state $j$ in year $t . \gamma_{t-n}$ are child year of birth fixed effects, controlling for the likely secular changes across birth cohorts born before 1999. The other variables are the same as in Equation (2).

\section{Estimation Results}

\subsection{Individual Ultrasound Use}

Our initial estimates show that while ultrasound use is positively correlated with sex-selection, this correlation has been weakening over time. Recall that the sample used in this specification consists only of most recently born children. The estimation results for Equation (1) are reported in Table 2. Column (1) shows that mother's ultrasound use is correlated with a 0.7 percentage point increase in the probability that a child is born male. In column (2), we incorporate a year trend and interaction term of a year trend and mother's ultrasound use into the analysis. In this specification, the positive correlation between mother's ultrasound use and whether the child is born male is even stronger and more than four times larger in magnitude. However, the interaction term in Column (2) indicates that the positive relationship between mother's ultrasound use and the sex of a child weakens over time. By the last year of the surveys, there is no longer a positive association between ultrasound use and the sex of a child at birth.

We further estimate Equation (1) with the subsample of most recently born children who are likely to be affected by sex-selection: most recently born children of birth order two through four who had no older brothers. Estimation results are reported in columns (3) and (4). Ultrasound use is associated with a 1.8 percentage point increase in the probability that a child is born a boy. In column (4), when year of birth and an ultrasound use and year-of-birth interaction term are included, similar to Column (2), we find that there is a decreasing trend over time in the correlation between ultrasound use and the probability that a child is born male. Again, 
by the end of the survey the relationship between ultrasound use and the child's sex at birth disappears.

[Table 2 about here.]

\subsection{Pre-Trends in State-Year Ultrasound Exposure and Sex-Selection}

Evidence presented in Table 2 suggests that a mother's individual ultrasound use is positively correlated with having a male child, although this correlation weakens over time. The OLS estimation above assumes that controlling for observables, the error term $\varepsilon_{i j t}$ is uncorrelated with mother's ultrasound use. However, if mothers that use ultrasound technology for sex-selective abortion are systematically different from the rest of the population in observable and unobservable ways, OLS estimation would be biased. To account for this concern, in the remainder of the paper, we use state-year level ultrasound exposure as our explanatory variable instead of a mother's actual ultrasound use (which we only know for her most recent pregnancy). We can only assume that the cross-state variation in intensity of ultrasound exposure, controlling for state fixed effects, is exogenous if the pre-1999 trends in sex-selection are unrelated to ultrasound exposure in the 2000s. Using Equation (3), we formally test whether trends in the probability of being born male in the 1980s and 1990s are related to trends in ultrasound exposure in the 2000s. These two estimations only use the birth histories reported in the DLHS II. ${ }^{10}$

We find that there is no relationship between the sex outcome of births in the 1980s and state-year level ultrasound exposure in the 2000s. The estimation results are presented in Table 3. The coefficient on ultrasound exposure is not significant at even the 10 percent level. ${ }^{11}$ Thus, there is no systematic difference in trends in the sex of children at birth between different states before the large-scale introduction of ultrasound.

As aforementioned, ultrasound became available in India starting in the 1990s; therefore

\footnotetext{
${ }^{10}$ The estimations in Table 3 may suffer from reporting bias, since the births happened well in the past compared to the date of the survey. We find quantitatively similar results if we instead use the Indian National Family Health Survey from 1992-1993, which would not be subject to this reporting bias.

${ }^{11}$ We find similar results when we control for state level GDP per capita in our analysis.
} 
it is possible that it was adopted in some Indian states earlier than others. We find that there is a positive relationship between trends in the probability of being born male in the 1990s and ultrasound exposure in the 2000s. The estimates are shown in In Table 4. The coefficient for ultrasound exposure indicates that a 50 percentage point increase in ultrasound exposure in the 2000 s is correlated with a 1.4 percentage point increase in the probability a child is born male in the 1990s. ${ }^{12}$ These estimates suggest that Indian states with rapidly growing ultrasound use in the 2000s were more likely to be using sex-selection in the 1990s. Therefore, we will not be able to claim that there is a causal relationship between ultrasound exposure and sexselection in the 2000s. However, knowing the pre-trends will allow us to better interpret our main estimation results.

[Table 3 about here.]

[Table 4 about here.]

\subsection{State-Year Ultrasound Exposure and Sex-Selection in the 2000s: Main Specification}

We find a statistically significant negative correlation between state-year level increases in ultrasound exposure from 1999 through 2008 and the probability of a male birth. That is, the more ultrasound that is used in a state, the less likely parents are to use sex-selective abortion. Results from estimation Equation (2) are presented in Table 5. The ultrasound exposure coefficient remains negative, of a similar magnitude, and statistically significant at the five percent level for all of the specifications. We estimate that a state with ultrasound exposure in a given year that is 50 percentage points higher compared to the state's initial ultrasound exposure in 1999 has a 1.3 percentage point decrease in the probability that a child is born male compared to a state with no increase in ultrasound exposure. This is a large correlation, given that a small percentage of total pregnancies end in a sex-selective abortion. ${ }^{13}$

\footnotetext{
${ }^{12}$ We find similar results when we control for state level GDP per capita in our analysis.

${ }^{13}$ Similar to previous studies, we also find that a mother's years of schooling is positively correlated with sexselection.
} 
Given that we find that there is a positive pre-1999 trend in sex-selection in states with rapidly growing ultrasound use in the 2000 s, we should be careful not to interpret our findings as implying a rise in ultrasound exposure caused a decline in sex-selective abortion in India. Rather, our findings suggest that Indian states with an already skewed sex-ratio at birth in 1999 were faster to adopt ultrasound technology in the 2000s. Moreover, we find that these states experienced a decline in sex-selection relative to the states which began 1999 with a more balanced sex-ratio at birth and slower adoption of ultrasound technology in the 2000s. Therefore, one can conclude that the rapid rise in ultrasound use in the 2000s cannot have caused a rapid increase in sex-selection in the 2000s. However, this does not imply that the fast growth in ultrasound use in some states of India directly lowered sex-selection there (see Figure 2). It only did so relative to those states with a slower rise in ultrasound use.

[Table 5 about here.]

\subsection{State-Year Ultrasound Exposure and Sex-Selection in the 2000s: Het- erogeneity and Robustness}

We have shown that ultrasound exposure is negatively associated with sex-selection in the population at large. However, it is of interest to estimate the heterogeneous effects of ultrasound exposure on sex-selection among different fractions of the population. We examine whether a rise in ultrasound has different associations with the probability a child is born male in rural versus urban households, households where the mothers are young versus old, and households where the mother has particularly low versus high levels of education. We find that the negative correlation between trends in ultrasound exposure and sex-selection only occurs in rural households. There is no relationship between ultrasound exposure and the probability a child is born male in an urban household. We also find that the negative relationship persists for children of mothers with low or high levels of education, although the correlation is stronger for mothers with a low level of education. In addition we perform robustness checks by dropping southern states from the sample, including state-level GDP and including a one-year lag of ultrasound 
exposure as independent variables. The estimates are robust to all of these specifications.

In columns (1) and (2) of Table 6, we split the sample into rural and urban populations, respectively. We find that an increase in ultrasound exposure is associated with a fall in sexselection in rural areas, while an increase in ultrasound exposure is unrelated to sex-selection in urban areas. Since ultrasound diffusion went from urban to rural parts of India (Khanna, 1997), it is possible that urban areas across India already had a high enough ultrasound availability to satiate demand for sex-selection in the 1990s, and thus we would not see any change in the 2000s. Thus, the recent rise in sex-selection in India may be occurring in rural areas that are just recently getting access to ultrasound.

In columns (3), (4), (5), and (6) we allow the ultrasound effects to vary by mothers' characteristics. Ultrasound is more likely to be used if a pregnancy is risky. The risk of pregnancy increases with the age of the mother, and mothers aged 35 and older should be closely monitored during their pregnancy; therefore they are more likely to use ultrasound for health reasons rather than sex-selective abortion. To account for this potential difference in ultrasound use, in column (3), the subsample is restricted to mothers who were age 30 or older at the time of birth, while in column (4) the subsample is restricted to mothers who were under age 30 at the time of birth. ${ }^{14}$ Although the estimated coefficient for older mothers is of the same magnitude in our full estimates, it is not statistically significant. The coefficient for younger mothers is of a similar size and is significant at the 5 percent level. Although the difference in significance could be coming from the smaller size of the older mothers sample, it is also plausible that the use of ultrasound for sex-selection is more common among younger mothers.

With the rapid economic development of India during the 1990s, ultrasound became widely available to households that had no or limited ex ante access. Therefore, it is possible that ultrasound exposure has the largest effect among disadvantaged households, proxied here by mothers without any schooling. We restrict the sample to mothers with zero years of education in Column (5) and eight or more years of education in column (6). The negative correlation between ultrasound exposure and the probability a child is born male is more than twice the

\footnotetext{
${ }^{14}$ Since the vast majority of mothers in our sample completed their fertility before age 35 , we use age 30 as a risk cut-off rather than age 35 .
} 
magnitude of the baseline specification.

Households with higher levels of education are those that have been found to be more likely to use sex-selective abortion. The coefficient on ultrasound exposure in column (6) is similar in magnitude to our baseline specification. However, the large gap in the ultrasound coefficient between the educated and uneducated mothers indicates that sex-selective abortion is falling relatively faster amongst the uneducated compared to the educated in states with rapid ultrasound expansion. In other words, the increase in sex-selection in the slow ultrasound growth states is occurring more rapidly among uneducated mothers. Similar to our urban/rural findings, these estimates fit the hypothesis that demand for ultrasound for sex-selection among better-off households in the 1990s was already largely satisfied in most states of India. Thus, the states where ultrasound growth is slower are the states where the rural and less educated are just starting to get access to sex-detection.

The last estimates determine whether our results are robust to alternative specifications. In column (7), states that are located in the south of India are dropped from the analysis since they are known to have historically more balanced sex ratios. These are states with fast growing ultrasound use, but little sex-selection. For example, Kerala has the highest rates of ultrasound use in India, but little evidence of sex-selection. Since ultrasound use in Kerala is likely due to the better availability of health care, rather than a desire for sex-selection, we test whether our negative coefficients are being driven by these southern outliers. The coefficient on ultrasound exposure in this column remains quantitatively similar to the baseline specification providing evidence that our results are not driven by a lack of selective abortion in the south.

In the 2000s, states with a higher ultrasound exposure may have been experiencing higher economic growth rates compared to states with lower ultrasound use, which may be responsible for the relative decline in sex-selection in these states. To assess whether the negative association between ultrasound exposure and sex-selection is explained by differential state growth rates, we control for state-year level GDP per capita between 1999 and 2007 in column (8). The point estimate on the ultrasound exposure coefficient slightly decreases when we control for state-year GDP per capita; however it is not statistically significantly different than the ul- 
trasound coefficient in the baseline results. Hence, the estimation results presented in Table 5 are not caused by differential economic growth.

Since women use ultrasound before giving birth, ultrasound availability for women in the year before giving birth may be a better measure of ultrasound availability. In Column (9), we use the one year lag of ultrasound exposure instead of ultrasound exposure in the year of birth itself. The estimates remain essentially unchanged.

[Table 6 about here.]

\subsection{State-Year Ultrasound Exposure and Selective Abortion in the 2000s: Conditional Child Sex Outcomes}

Previous research has documented that sex-selective abortion is not prevalent at the first pregnancy; however it increases with birth order (Jha et al., 2011; Bhalotra and Cochrane, 2010; Portner, 2010; Rosenblum, 2010). Furthermore, sex-selection has only been detected at higher parities if there is no older male sibling. We want to ensure our findings are not simply an artifact of our data. Thus, we confirm that our estimates are consistent with knowledge about which births are at high risk of sex-selection. In particular, we estimate the correlation between ultrasound exposure and the probability that a second-born child is male conditional on the first-born child being female, as well as the probability that a third-born child is male conditional on the first two children being born female. Parents do not report their full birth histories in the DLHS III. However, they do report the total number of sons and daughters born. Thus, we can impute the number of sons or daughters born before the most recent birth.

We find no relationship between ultrasound exposure and the sex of the child if there were older brothers, which is consistent with previous findings that sex-selective abortion does not occur for these groups. However, we find that there is a large and statistically significant negative association between ultrasound exposure and sex-selection for children of parity two conditional on the first-born child being female. Since this is the group for which parents are most likely to use sex-selection, our negative and statistically significant coefficient adds fur- 
ther evidence to the empirical finding that increases in ultrasound use are negatively related to sex-selection.

Table 7 presents estimates for the subset of children of birth order two and three conditional on the sex of the older sibling(s). In columns (1) and (3), the sample consists of children of birth order two and shows estimates of sex-selection of these children conditional on the older sibling being male (column 1) or female (column 3). The table also shows estimates for the subset of children of birth order three conditional on the two older siblings being male (column 2) or female (column 4). Though the coefficient in column (4), for parity three children with two older sisters, is of a similar magnitude and direction as to what we find in our main results, it is not statistically significant at the ten percent level. This lack of statistical significance is possibly due to the small sample size of this group.

[Table 7 about here.]

\section{Conclusion}

We find consistent evidence that the rapid rise in ultrasound use in India in the 2000s cannot have caused a rise in sex-selection. Rather, our findings suggest that the states of India with a faster growth in ultrasound use are the states with a relative decline in sex-selection. We also find that states with a rapid increase in sex-selection in the 1990s had an upsurge in ultrasound use in the 2000s, with some states doubling or tripling average ultrasound use over the 2000s. And, yet, there was no disastrous explosion in sex-selective abortion for these states. Therefore, our findings suggest that ultrasound has been increasingly used for health care rather than sexselection in India in the 2000s.

The diffusion of ultrasound in India may correspond to a selection story. Parents who wanted to use ultrasound for sex-selective abortion are the ones who first got access to ultrasound because they were willing to pay the most for the technology. After this initial spread of ultrasound, parents who want to use it for health reasons rather than sex-selective abortion are more likely to ask for this service. If this is true, then an increase in ultrasound use will be 
negatively correlated with sex-selection.

Another possibility is that it is not the trends in ultrasound exposure that matter for adopting sex-selection, but a critical level of ultrasound exposure. Those states with rapidly growing ultrasound use may have passed that threshold before 1999 and have already obtained a sexratio that is close to equilibrium. The states with slow-growing ultrasound have just started to pass this threshold in the 2000s. Therefore, we may see convergence in sex-selective abortion between the slow and fast growing ultrasound use states, even if the growth rates in ultrasound exposure have diverged.

Sex-detection has been illegal in India since the passage of the Pre-Natal Diagnostic Techniques Act of 1994 (and put into effect in 1996). Another possible explanation for our findings, is that India may be differentially enforcing laws against sex-selection. In states with a rapid increase in ultrasound use, the government may be putting more resources into combating sexselection, and, thus, allowing a relative rise in sex-selection in states with a slow increase in ultrasound use. ${ }^{15}$

Findings in this paper should both comfort and concern policy makers in India. On the one hand, our findings indicate that the rapid spread of ultrasound is unlikely to further exacerbate the sex-selection problem in India. Thus, the possibly significant health benefits of greater access to ultrasound do not need to be balanced with a fear of increasing misuse. On the other hand, if the spread of ultrasound is not responsible for rising sex-selective abortion in some parts of India, then stopping sex-selection will be more difficult than controlling ultrasound use. Indeed, the reasons for sex-selection are likely far more complicated than the simple spread of sex-detection technology.

\footnotetext{
${ }^{15}$ Nandi and Deolalikar (2011) find that the earlier implementation of laws against sex-detection in Maharashtra reduced sex-selection there relative to the nearby parts of India that later introduced such laws. Maharashtra passed laws against sex-detection in 1988, whereas the Pre-Natal Diagnostics Technique Act was implemented nationally in 1996. However, Portner (2010) finds that these later laws were ineffective at reducing sex-selection.
} 


\section{References}

Anderson, Siwan and Debraj Ray, "Missing Women: Age and Disease," BREAD Working Paper, 2008, 176.

Arnold, Fred and Sulabha Parasuraman, "The Effect of Ultrasound Testing during Pregnancy on Pregnancy Termination and the Sex Ratio at Birth in India,' 2009. Paper presented at the XXVI International Population Conference, International Union for the Scientific Study of Population, Marrakech, 27 September-2 October.

_, Sunita Kishor, and T.K. Roy, "Sex-Selective Abortions in India," Population and Development Review, 2002, 28 (4), 759-785.

Bhalotra, Sonia and Tom Cochrane, "Where Have All the Young Girls Gone? Identification of Sex Selection in India," IZA Discussion Paper, 2010, 5381.

Chen, Yuyu, Hongbin Li, and Lingsheng Meng, "Prenatal Sex Selection and Missing Girls in China: Evidence from the Diffusion of Diagnostic Ultrasound," 2011. working paper.

Coale, Ansley, "Excess Female Mortality and the Balance of the Sexes in the Population: An Estimate of the number of 'Missing Females',' Population and Development Review, 1991, $17(3), 517-523$.

Ebenstein, Avraham, "Fertility Decision and Sex Selection in Asia: Analysis and Policy," 2007. Mimeo.

Ganatra, Bela and Siddhi Hirve, "Induced Abortions among Adolescent Women in Rural Maharashtra, India," Reproductive Health Matters, 2002, 19 (19), 76-85.

George, Sabu, “Sex ratio in India,” Lancet, 2006, 367 (9524), 1725.

Hvistendahl, Mara, Unnatural Selection: Choosing Boys Over Girls, and the Consequences of a World Full of Men, New York: Public Affairs, 2011. 
Jha, Prabhat, Maya Kesler, Rajesh Kumar, Usha Ram, Lukasz Aleksandowicz, Diego Bassani, Shailaja Chandra, and Jayant Banthia, "Trends in selective abortions in India: Analysis of nationally representative birth histories from 1990 to 2005 and census data from 1991 to 2011," Lancet, 2011, 377 (9781), 1921-1928.

_, Rajesh Kumar, Priya Vasa, Neeraj Dhingra, Deva Thiruchelvam, and Rahim Moineddin, "Low male-to-female sex ratio of children born in India: national survey of 1.1 million households," Lancet, 2006, 367 (9506), 211-218.

Khanna, S.K., "Traditions and reproductive technology in an urbanizing north Indian village," Social Science and Medicine, 1997, 44 (2), 171-180.

Klasen, Stephan, “'Missing women' reconsidered," World Development, 1994, 22, 10611071.

Nandi, Arindam and Anil B. Deolalikar, "Does a Legal Ban on Sex-Selective Abortions Improve Child Sex Ratios? Evidence from a Policy Change in India," 2011. Available at SSRN: http://ssrn.com/abstract $=1824420$.

Portner, Claus C., "Sex Selective Abortions, Fertility and Birth Spacing," University of Washington, Department of Economics, Working Paper, 2010, UWEC-2010-4.

Rosenblum, Daniel, "The Effect of Fertility Decisions on Excess Female Mortality in India," 2010. Mimeo.

_, "Economic Incentives for Sex-Selective Abortion in India," 2011. Mimeo.

Sen, Amartya, "More Than 100 Million Women are Missing," The New York Review of Books, 1990, $37(20)$.

Wonacott, Peter, "India's Skewed Sex Ratio Puts GE Sales in Spotlight," The Wall Street Journal, 2007, April 18, A1. 


\section{A Indian Census Graphs}

For additional evidence that growth in ultrasound use may not be causing sex-selection, we present state-level graphs grouped by region for the number of females per 1000 males, age 0-6, from the 1991, 2001, and 2011 Indian Censuses. For comparison, sex ratios at birth in developed countries are in the 950-975 range, which rises as children age because boys are more likely to die at young ages than girls (assuming equal care). In the United States' 2010 Census, there were 958 females per 1000 males for children under age 5. Many of the states of India are close to this reference group, with most exceptions being in the north, center, and west. The census sex ratios reflect both the effects of sex-selective abortion and excess female mortality, and thus the more specific estimates of child sex at birth in this paper are a better measure of the effect of ultrasound use on sex-selection. Nevertheless, the census data is as accurate as one can get for an estimate of the actual sex-ratio in India and represents the trends in the overall demographic outcomes of the Indian population.

North India, albeit experiencing large drops in the number of girls from 1991 to 2001, shows little change in the number of females from 2001 to 2011. If anything, most of the states show improving sex ratios over the last ten years even with an almost quadrupling of reported ultrasound use. For instance, child sex ratios in south India have generally remained flat over the three censuses, even though it is the region with the largest increase in ultrasound use. The east and northeast have several states showing a worsening trend in child sex ratios over time, and yet they have only had modest increases in ultrasound use. Taken together, the regional trends presented in Appendix A suggests that the places where ultrasound is spreading quickly are not the places where child sex ratios are getting significantly worse.

[Figure 5 about here.]

[Figure 6 about here.]

[Figure 7 about here.]

[Figure 8 about here.] 
[Figure 9 about here.] 


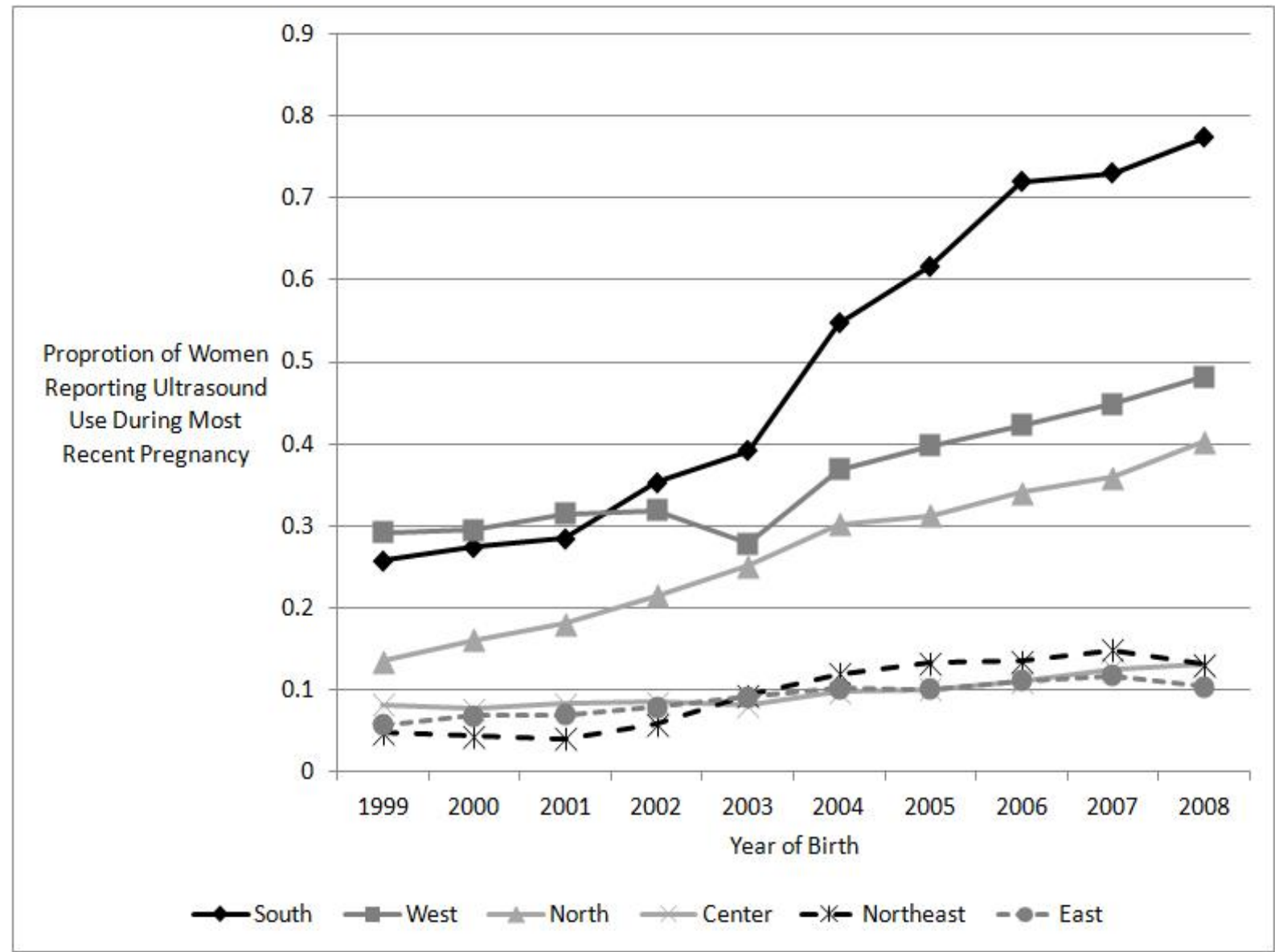

Figure 1: Proportion of women reporting ultrasound use during most recent pregnancy. Only pregnancies that resulted in a live birth are included. Data Source: DLHS II and DLHS III. 


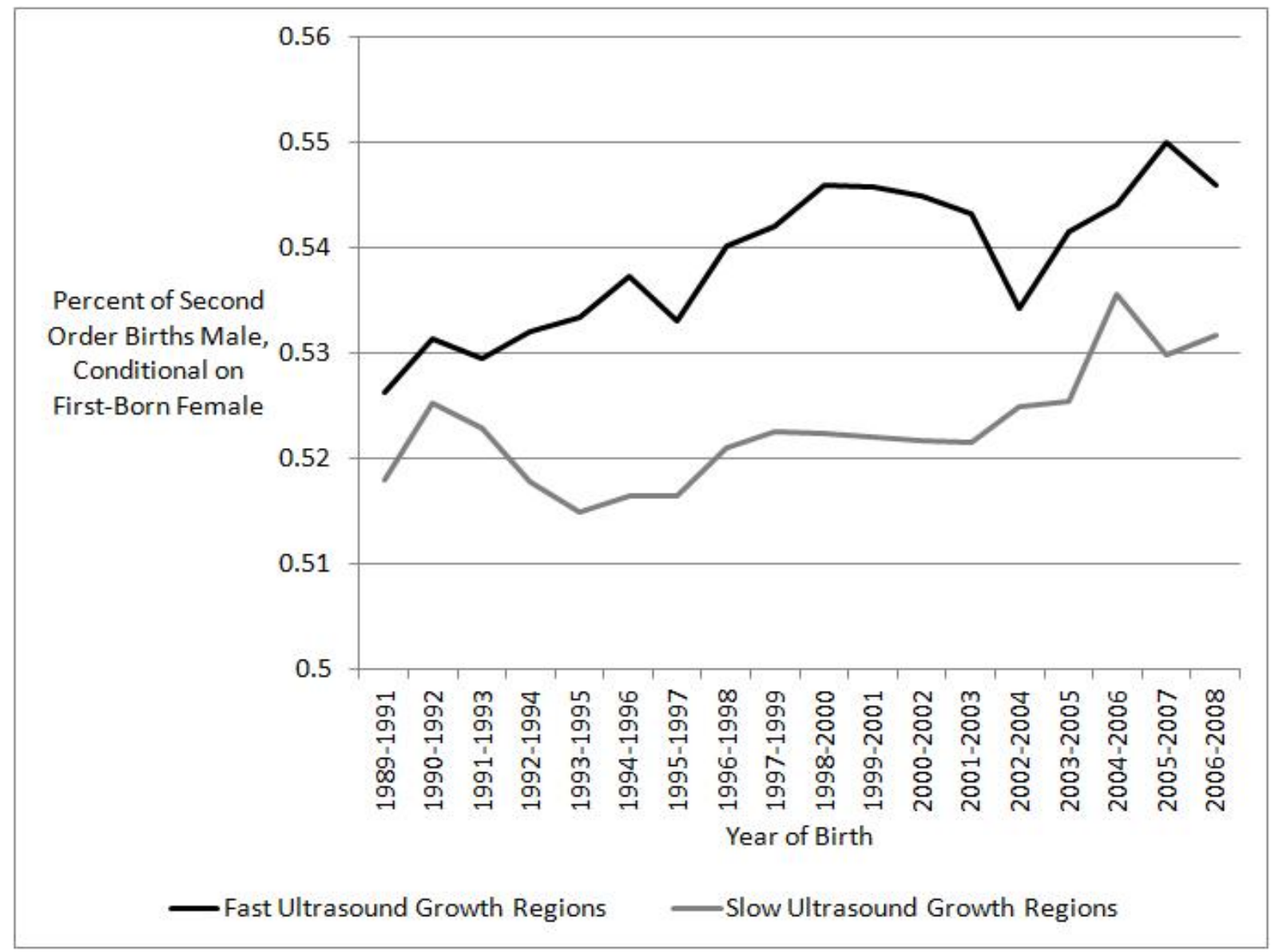

Figure 2: Shrinking gap in the sex-ratio at birth in regions with fast versus slow growth in ultrasound exposure. Fast growth regions are the north, west, and south. Slow growth regions are the center, northeast, and east. Data Source: DLHS II and DLHS III. 


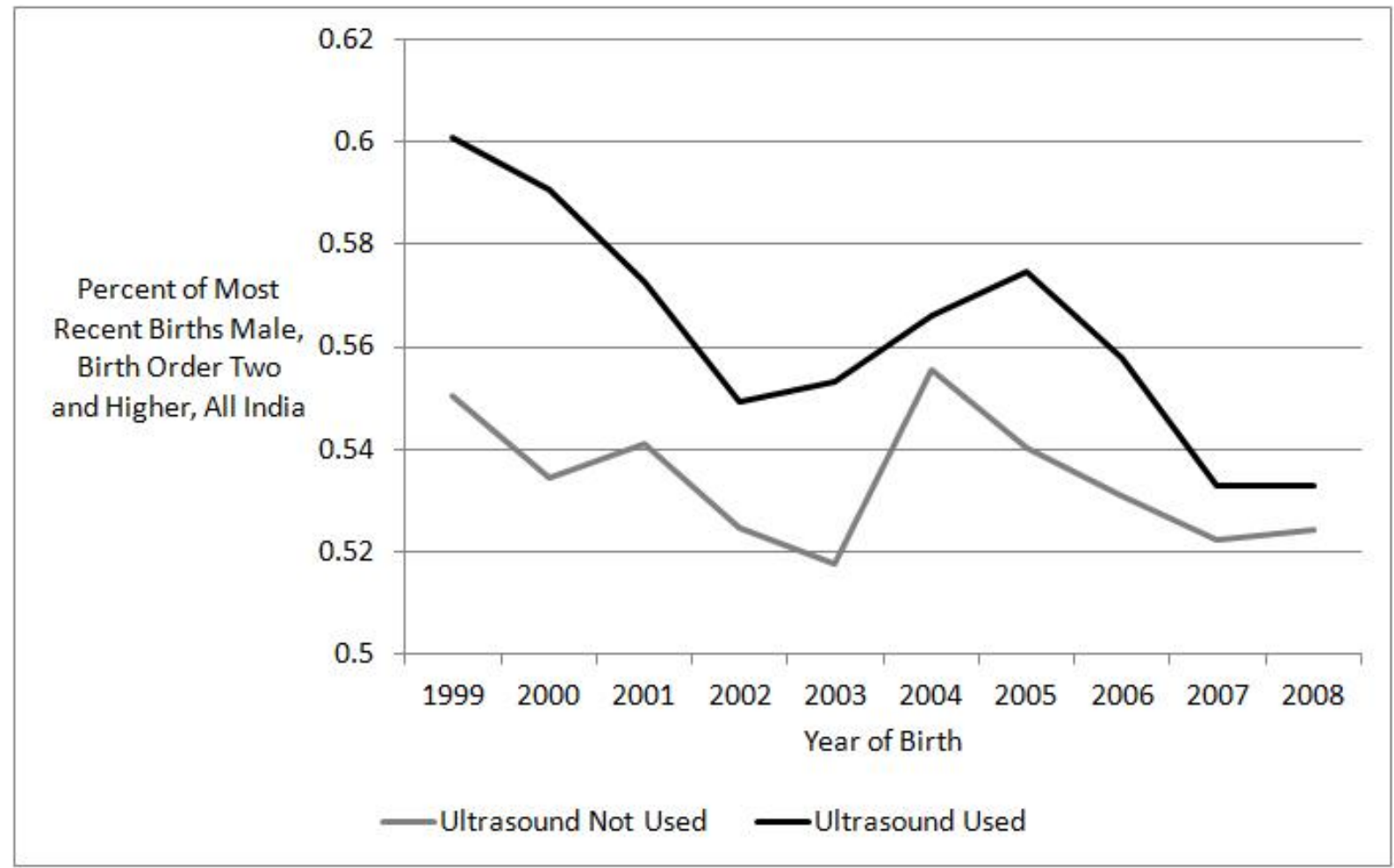

Figure 3: Percent of most recent births male by ultrasound use, second and higher order children. Data Source: DLHS II and DLHS III. 


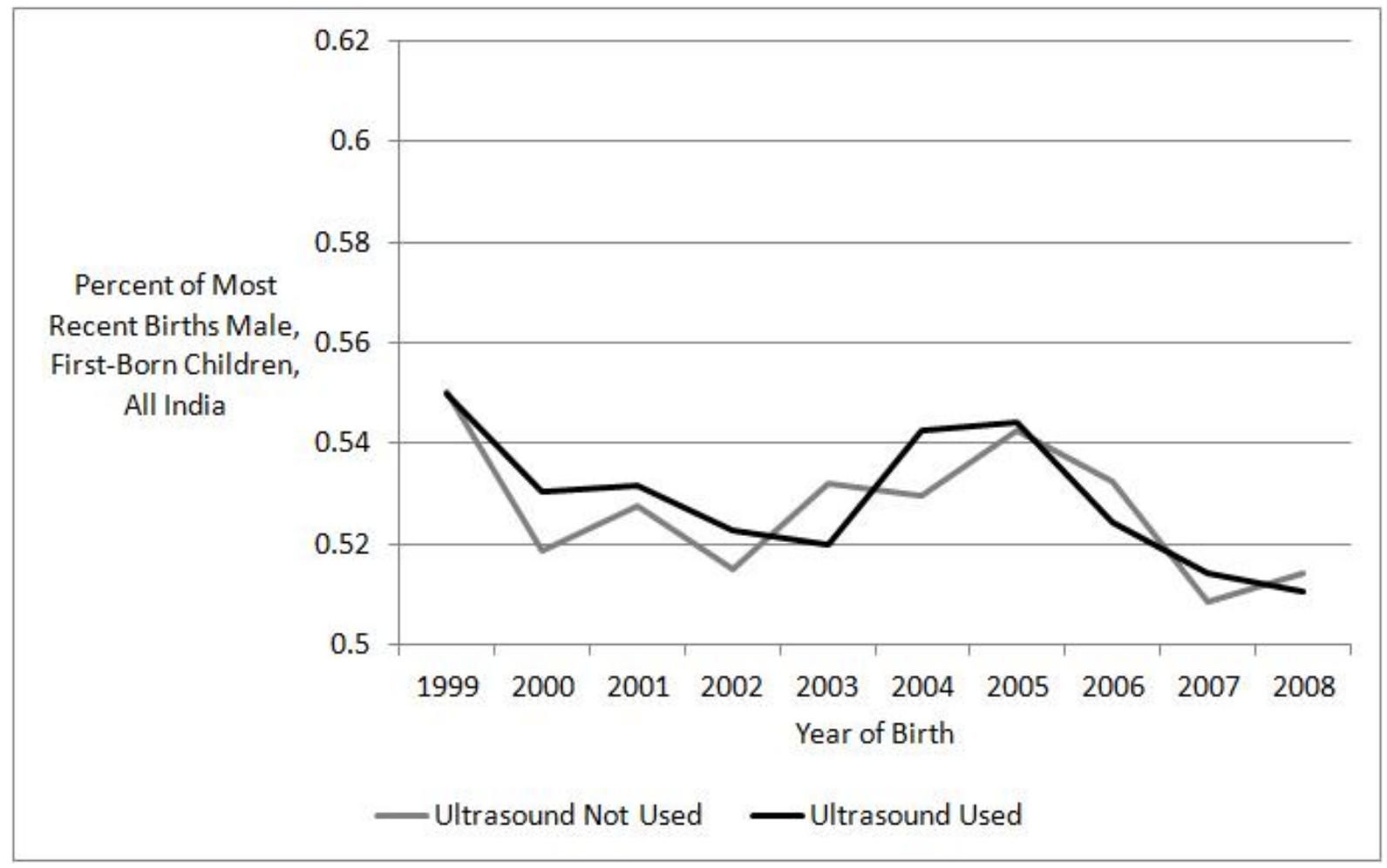

Figure 4: Percent of most recent births male by ultrasound use, first-born children. Data Source: DLHS II and DLHS III. 


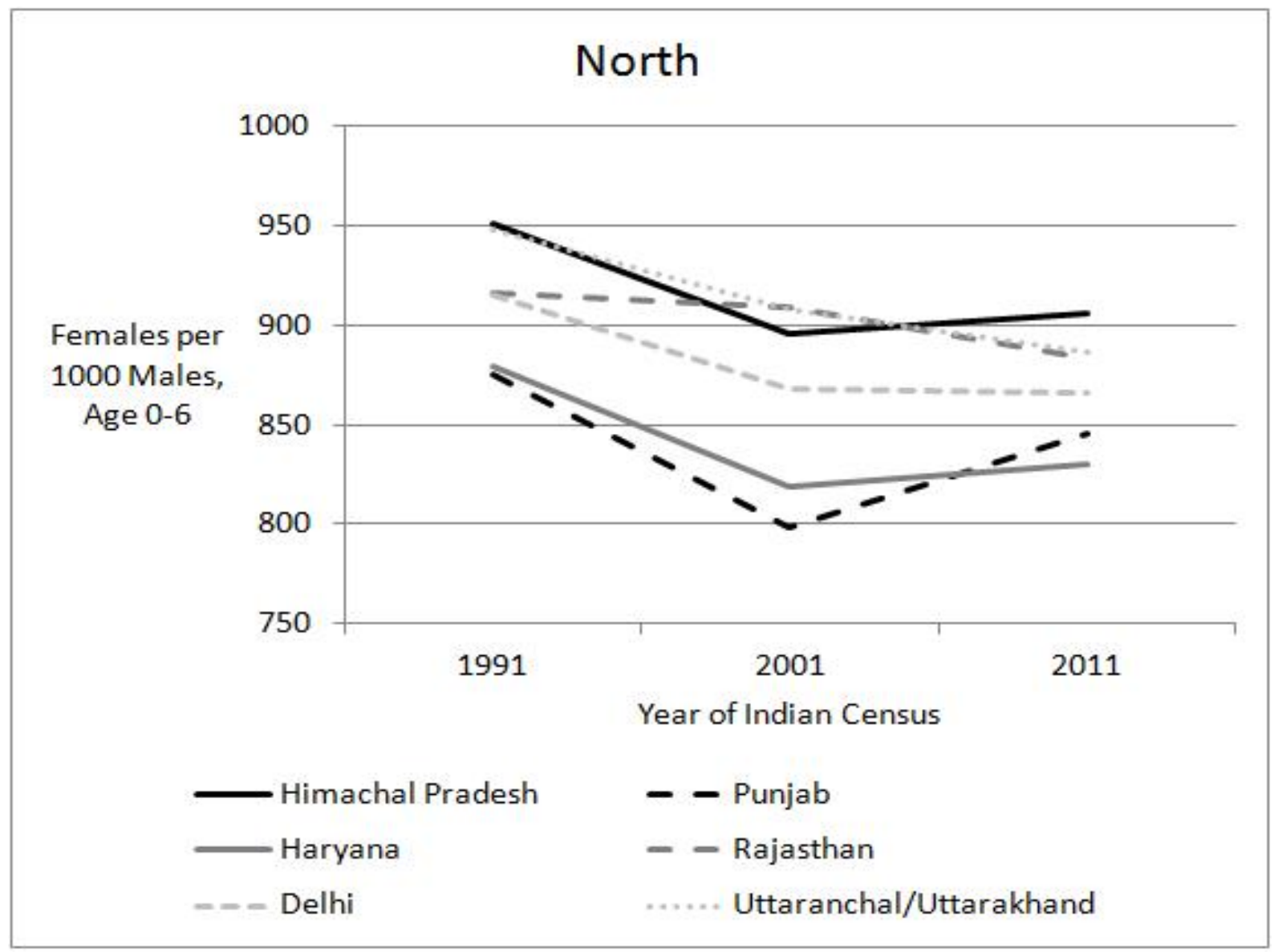

Figure 5: Child Female-Male Sex Ratio: North. Data Source: Indian Census 1991, 2001, and 2011. 


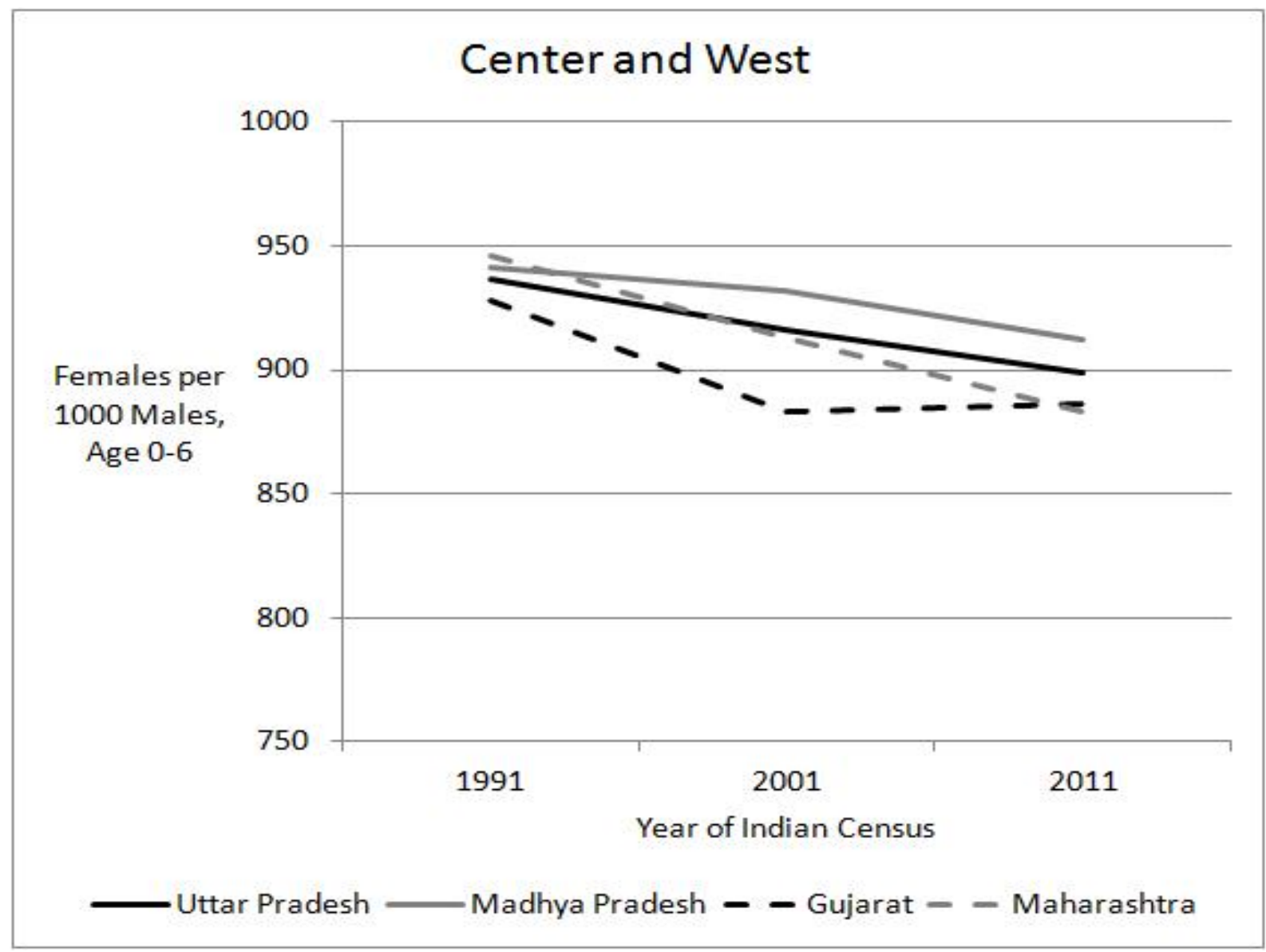

Figure 6: Child Female-Male Sex Ratio: Center (solid lines) and West (dashed lines). Data Source: Indian Census 1991, 2001, and 2011. 


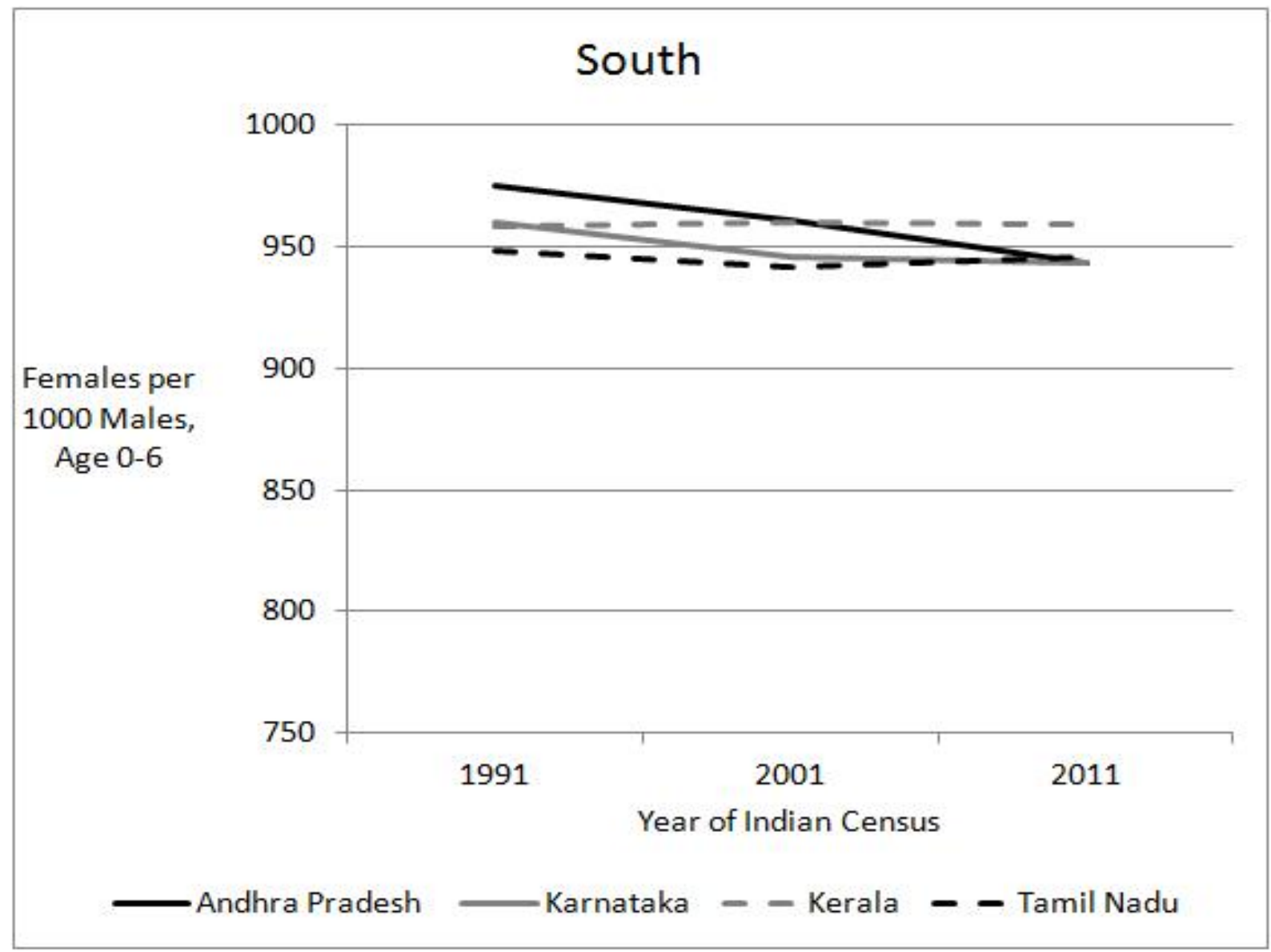

Figure 7: Child Female-Male Sex Ratio: South. Data Source: Indian Census 1991, 2001, and 2011. 


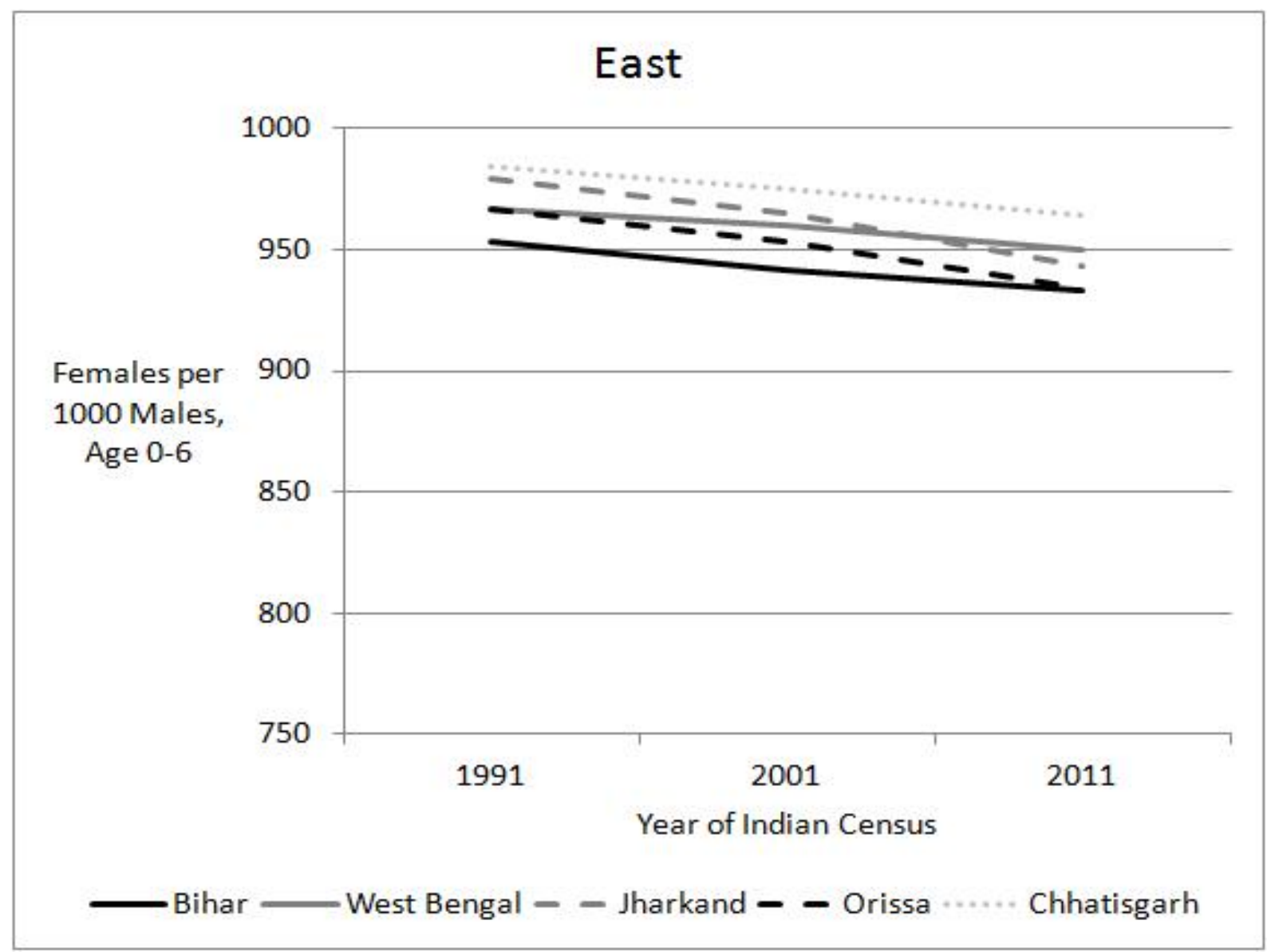

Figure 8: Child Female-Male Sex Ratio: East. Data Source: Indian Census 1991, 2001, and 2011. 


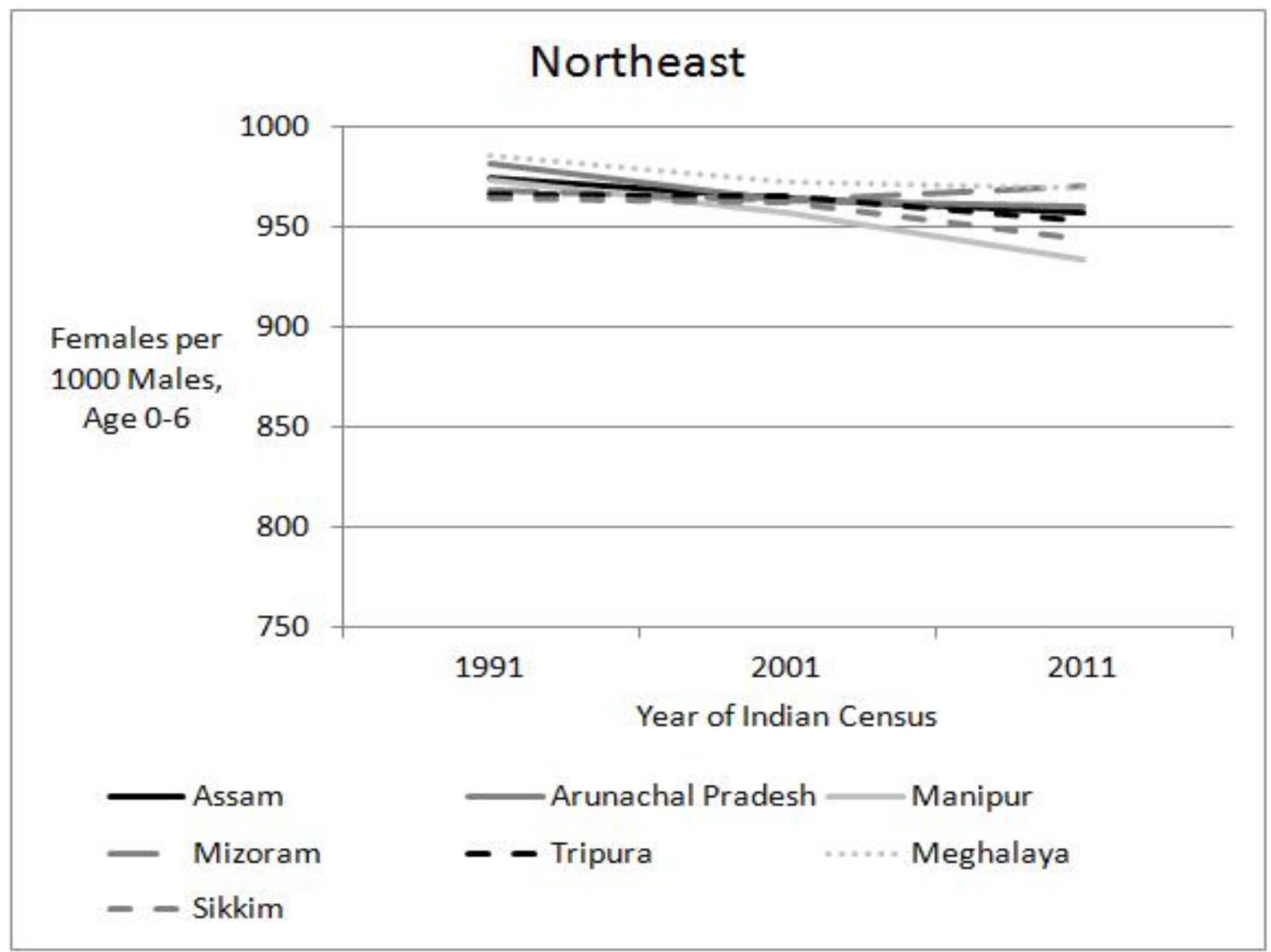

Figure 9: Child Female-Male Sex Ratio: Northeast. Data Source: Indian Census 1991, 2001, and 2011. 
Table 1: Descriptive Statistics

\begin{tabular}{lccccc}
\hline \hline & First-Born & Second-Born & Third-Born & Fourth-Born & All \\
& $(1)$ & $(2)$ & $(3)$ & $(4)$ & $(5)$ \\
\hline Child is a Boy & 0.519 & 0.523 & 0.528 & 0.523 & 0.523 \\
& $(0.500)$ & $(0.499)$ & $(0.499)$ & $(0.499)$ & $(0.499)$ \\
Ultrasound Exposure & 0.221 & 0.216 & 0.182 & 0.155 & 0.203 \\
& $(0.191)$ & $(0.188)$ & $(0.164)$ & $(0.142)$ & $(0.181)$ \\
Mother's Years of Schooling & 6.015 & 5.126 & 3.476 & 2.329 & 4.751 \\
& $(5.102)$ & $(4.940)$ & $(4.293)$ & $(3.657)$ & $(4.904)$ \\
Father's Years of Schooling & 7.880 & 7.299 & 6.132 & 5.196 & 7.001 \\
& $(4.922)$ & $(4.965)$ & $(4.845)$ & $(4.721)$ & $(4.983)$ \\
Mother's Age at Birth & 20.59 & 22.79 & 24.55 & 26.52 & 22.84 \\
& $(3.636)$ & $(3.890)$ & $(3.981)$ & $(4.166)$ & $(4.354)$ \\
Rural & 0.728 & 0.741 & 0.784 & 0.815 & 0.755 \\
& $(0.445)$ & $(0.438)$ & $(0.411)$ & $(0.388)$ & $(0.430)$ \\
Hindu & 0.772 & 0.771 & 0.752 & 0.729 & 0.762 \\
& $(0.419)$ & $(0.420)$ & $(0.432)$ & $(0.444)$ & $(0.426)$ \\
Muslim & 0.117 & 0.119 & 0.138 & 0.161 & 0.128 \\
& $(0.322)$ & $(0.324)$ & $(0.345)$ & $(0.368)$ & $(0.334)$ \\
Christian & 0.0557 & 0.0578 & 0.0637 & 0.0682 & 0.0596 \\
& $(0.229)$ & $(0.233)$ & $(0.244)$ & $(0.252)$ & $(0.237)$ \\
Backwards Classes & 0.391 & 0.394 & 0.393 & 0.392 & 0.393 \\
& $(0.488)$ & $(0.489)$ & $(0.489)$ & $(0.488)$ & $(0.488)$ \\
Scheduled Caste & 0.171 & 0.176 & 0.195 & 0.202 & 0.182 \\
& $(0.377)$ & $(0.381)$ & $(0.396)$ & $(0.402)$ & $(0.386)$ \\
Scheduled Tribe & 0.155 & 0.161 & 0.187 & 0.206 & 0.170 \\
& $(0.362)$ & $(0.368)$ & $(0.390)$ & $(0.405)$ & $(0.376)$ \\
\hline Observations & 176048 & 157849 & 102688 & 62280 & 498865 \\
\hline \hline
\end{tabular}

Notes: Standard errors are reported in parentheses. In the analysis, we include variables for Sikh, Jain, and Buddhist. Because these groups represent less than three percent of observations, their means and standard errors are not reported here. Data source: DLHS II and DLHS III. 
Table 2: Mother's ultrasound use and the probability the most recently born child is male.

\begin{tabular}{lcccc}
\hline \hline & \multicolumn{2}{c}{ Birth Order 1-4 } & \multicolumn{2}{c}{ Birth Order 2-4 } \\
& \multicolumn{2}{c}{ No Older Brothers } \\
& $0.007^{* *}$ & $0.026^{* * *}$ & $0.018^{* *}$ & $0.055^{* * *}$ \\
\hline Ultrasound & $(0.003)$ & $(0.008)$ & $(0.007)$ & $(0.013)$ \\
& & $-0.003^{* *}$ & & $-0.006^{* * *}$ \\
Ultrasound*Year & & $(0.001)$ & $(0.002)$ \\
& & $-0.002^{* * *}$ & & $-0.003^{* * *}$ \\
Year of Birth & & $(0.000)$ & & $(0.001)$ \\
& 0.0019 & 0.0020 & 0.0100 & 0.0106 \\
R-Squared & 330974 & 330938 & 79428 & 79417 \\
Observations & Yes & Yes & Yes & Yes \\
\hline \hline Household Variables & Yes & Yes & Yes & Yes \\
State Fixed Effects & &
\end{tabular}

Notes: Robust standard errors, clustered at the state level, are reported in parentheses. Columns (1) and (2) are estimates for the full sample of most recent births of birth order 1 through 4 . Columns (3) and (4) are estimates for the sample of most recent births of birth order 2 through 4 with no older brothers. Household variables include: mother's years of schooling, father's years of schooling, mother's age at birth, birth order dummies, a rural dummy, and religion and caste dummy variables. Data Source: DLHS II and DLHS III.

$(* p<0.1, * * p<0.05, * * * p<0.01)$ 
Table 3: Ultrasound exposure and the probability the most recently born child is male, 20-year birth-year lag (1980s).

\begin{tabular}{lcccc}
\hline \hline & $(1)$ & $(2)$ & $(3)$ & $(4)$ \\
\hline Ultrasound Exposure & -0.0167 & -0.0166 & -0.0165 & -0.0166 \\
& $(0.0217)$ & $(0.0218)$ & $(0.0218)$ & $(0.0217)$ \\
Mother's Years of Schooling & & -0.0003 & -0.0003 & -0.0004 \\
& & $(0.0003)$ & $(0.0003)$ & $(0.0003)$ \\
Father's Years of Schooling & & 0.0000 & 0.0000 & -0.0000 \\
& & $(0.0003)$ & $(0.0002)$ & $(0.0002)$ \\
\hline R-Squared & 0.0008 & 0.0009 & 0.0009 & 0.0009 \\
Observations & 309048 & 309048 & 309048 & 309046 \\
\hline \hline State and Year of Birth FE & Yes & Yes & Yes & Yes \\
Mother's Age at Birth, Rural, Birth Order & No & Yes & Yes & Yes \\
Religion & No & No & Yes & Yes \\
Caste & No & No & No & Yes \\
\hline
\end{tabular}

Notes: Robust standard errors, clustered at state level, are reported in parentheses. Children with birth order 4 or less are included in the analysis. Births in year 19XX are assigned ultrasound exposures in the year 19XX+20. Birth years are 1979 through 1988. Data Source: DLHS II.

$(* p<0.1, * * p<0.05, * * * p<0.01)$ 
Table 4: Ultrasound exposure and the probability the most recently born child is male, 10-year birth-year lag (1990s).

\begin{tabular}{lcccc}
\hline \hline & $(1)$ & $(2)$ & $(3)$ & $(4)$ \\
\hline Ultrasound Exposure & $0.0280^{* *}$ & $0.0274^{* *}$ & $0.0274^{* *}$ & $0.0274^{* *}$ \\
& $(0.0114)$ & $(0.0113)$ & $(0.0113)$ & $(0.0114)$ \\
Mother's Years of Schooling & & 0.0003 & 0.0003 & 0.0001 \\
& & $(0.0002)$ & $(0.0002)$ & $(0.0002)$ \\
Father's Years of Schooling & & $0.0003^{* *}$ & $0.0003^{* *}$ & 0.0002 \\
& & $(0.0001)$ & $(0.0001)$ & $(0.0001)$ \\
\hline R-Squared & 0.0003 & 0.0004 & 0.0004 & 0.0004 \\
Observations & 573371 & 573371 & 573371 & 573371 \\
\hline \hline State and Year of Birth FE & Yes & Yes & Yes & Yes \\
Mother's Age at Birth, Rural, Birth Order & No & Yes & Yes & Yes \\
Religion & No & No & Yes & Yes \\
Caste & No & No & No & Yes \\
\hline Nastes
\end{tabular}

Notes: Robust standard errors, clustered at state level, are reported in parentheses. Children with birth order 4 or less are included in the analysis. Births in year 19XX are assigned ultrasound exposures in the year 19XX+10. Birth years are 1989 through 1998. Data Source: DLHS II.

$\left(* p<0.1,{ }^{* *} p<0.05, * * * p<0.01\right)$ 
Table 5: Ultrasound exposure and the probability the most recently born child is male (2000s).

\begin{tabular}{lcccc}
\hline \hline & $(1)$ & $(2)$ & $(3)$ & $(4)$ \\
\hline Ultrasound Exposure & $-0.0226^{* *}$ & $-0.0259^{* *}$ & $-0.0266^{* *}$ & $-0.0262^{* * *}$ \\
Mother's Years of Schooling & $(0.0091)$ & $(0.0095)$ & $(0.0098)$ & $(0.0095)$ \\
& & $0.0014^{* * *}$ & $0.0014 * * *$ & $0.0012^{* * *}$ \\
Father's Years of Schooling & & $(0.0003)$ & $(0.0003)$ & $(0.0002)$ \\
& & $0.0003 * *$ & 0.0003 & 0.0002 \\
\hline R-Squared & & $(0.0002)$ & $(0.0002)$ & $(0.0002)$ \\
Observations & 0.0004 & 0.0007 & 0.0008 & 0.0008 \\
\hline State and Year of Birth FE & 498865 & 498865 & 498860 & 498622 \\
Mother's Age at Birth, Rural, Birth Order & Yes & Yes & Yes & Yes \\
Religion & No & Yes & Yes & Yes \\
Caste & No & No & Yes & Yes \\
\hline
\end{tabular}

Notes: Robust standard errors, clustered at state level, are reported in parentheses. Children with birth order 4 or less are included in the analysis. Data Source: DLHS II and DLHS III.

$(* p<0.1, * * p<0.05, * * * p<0.01)$ 


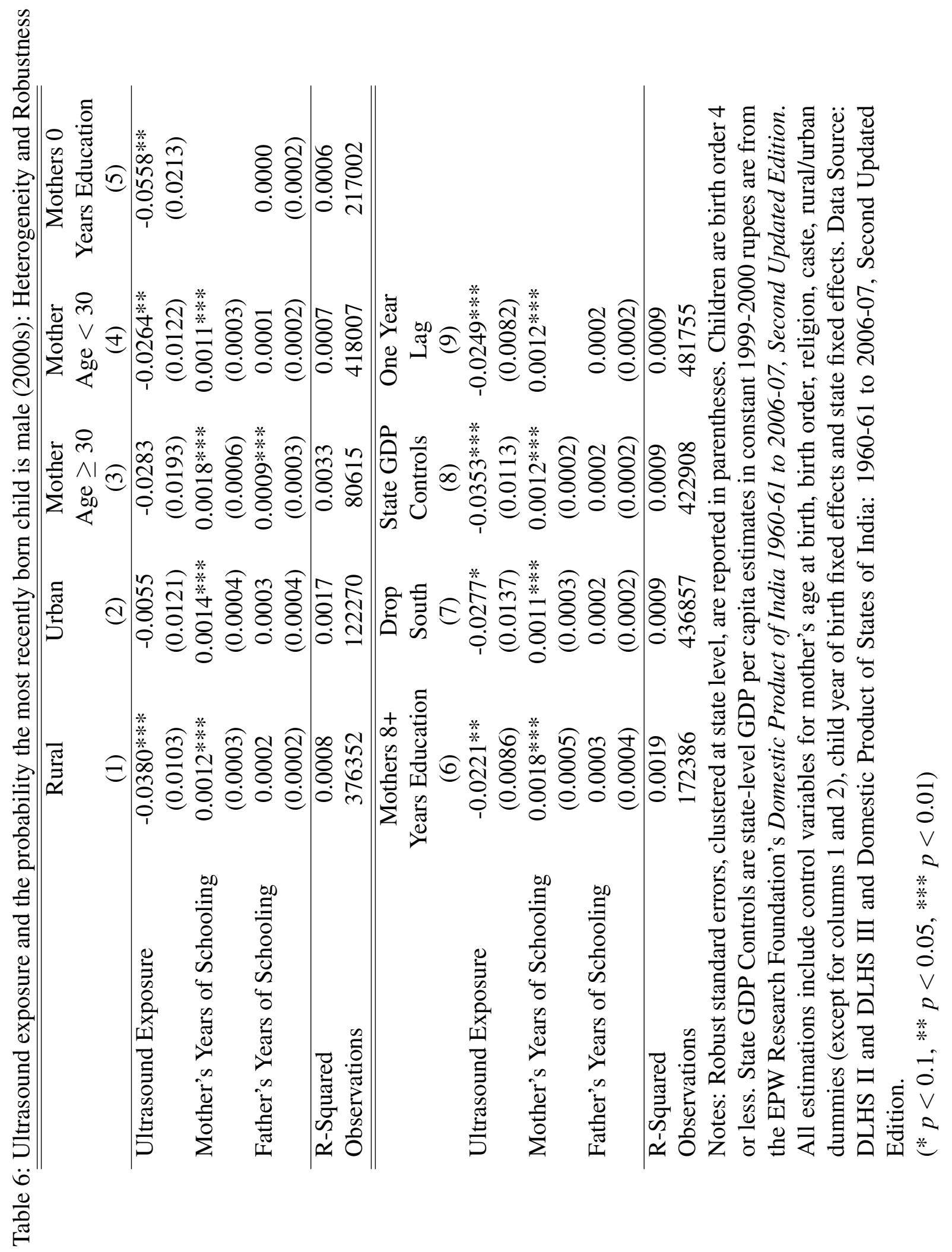


Table 7: Ultrasound exposure and the probability the most recently born child is male (2000s): By birth order, conditional on the sex of older siblings.

\begin{tabular}{lcccc}
\hline \hline & Parity 2 & Parity 3 & Parity 2 & Parity 3 \\
& $\mathrm{B}$ & $\mathrm{BB}$ & $\mathrm{G}$ & $\mathrm{GG}$ \\
& $(1)$ & $(2)$ & $(3)$ & $(4)$ \\
Ultrasound Exposure & 0.0072 & -0.0034 & $-0.0581^{* *}$ & -0.0287 \\
& $(0.0183)$ & $(0.0289)$ & $(0.0258)$ & $(0.0630)$ \\
Mother's Years of Schooling & 0.0000 & -0.0014 & $0.0029 * * *$ & $0.0068 * * *$ \\
& $(0.0006)$ & $(0.0011)$ & $(0.0005)$ & $(0.0011)$ \\
Father's Years of Schooling & -0.0003 & -0.0006 & $0.0013 * * *$ & $0.0017 *$ \\
& $(0.0004)$ & $(0.0008)$ & $(0.0004)$ & $(0.0009)$ \\
\hline R-Squared & 0.0010 & 0.0055 & 0.0054 & 0.0129 \\
Observations & 77552 & 22289 & 74822 & 27823 \\
\hline \hline
\end{tabular}

Notes: Robust standard errors, clustered at state level, are reported in parentheses. Children are birth order four or less. All estimations include control variables for mother's age at birth, birth order, religion, caste, rural/urban dummies, child year of birth fixed effects and state fixed effects. B indicates first-born child is male. BB indicates first and second born children are male. $G$ indicates first-born child is female. GG indicates first and second-born children are female. Data Source: DLHS II and DLHS III.

$(* p<0.1, * * p<0.05, * * * p<0.01)$ 